\begin{tabular}{ll|l} 
Case Reports in & \multicolumn{2}{c}{ Case Rep Gastroenterol 2013;7:182-187 } \\
\cline { 2 - 3 } Gastroenterology & $\begin{array}{l}\text { DOI: } 10.1159 / 000350673 \\
\text { Published online: March 28, 2013 }\end{array}$ & $\begin{array}{l}\text { ○ 2013 S. Karger AG, Basel } \\
\text { 1662-0631/13/0071-0182 } \$ 38.00 / 0 \\
\text { www.karger.com/crg }\end{array}$ \\
\hline & $\begin{array}{l}\text { This is an Open Access article licensed under the terms of the Creative Commons Attribution- } \\
\text { NonCommercial-NoDerivs 3.0 License (www.karger.com/OA-license), applicable to the } \\
\text { online version of the article only. Distribution for non-commercial purposes only. }\end{array}$
\end{tabular}

\title{
Successful Resection of Intracranial Metastasis of Hepatocellular Carcinoma
}

\author{
Kenichiro Okimoto ${ }^{a}$ Sadahisa Ogasawara ${ }^{a}$ Tetsuhiro Chiba ${ }^{a}$ \\ Fumihiko Kanai $^{a}$ Hajime Yokota ${ }^{b}$ Tenyu Motoyama ${ }^{a}$ Eiichiro Suzuki ${ }^{a}$ \\ Yoshihiko Ooka $^{a}$ Akinobu Tawada $^{a}$ Yasuo Iwadate $^{c}$ Naokatsu Saeki ${ }^{c}$ \\ Osamu Yokosuka ${ }^{a}$ \\ Departments of ${ }^{\mathrm{a}}$ Gastroenterology and Nephrology, ${ }^{\mathrm{b}}$ Radiology and ${ }^{\mathrm{C}}$ Neurological \\ Surgery, Graduate School of Medicine, Chiba University, Chiba, Japan
}

\section{Key Words}

Hepatocellular carcinoma · Surgical resection · Intracranial metastasis

\begin{abstract}
Intracranial metastasis of hepatocellular carcinoma $(\mathrm{HCC})$ is rare, but has an extremely poor prognosis. We report a case with successful surgical removal of intracranial metastasis of HCC. A 32-year-old man was admitted to our hospital with severe vomiting. He had been followed for liver cirrhosis due to hepatitis $B$ virus infection and received a right hepatic trisectionectomy for HCC 1 year earlier. For the recurrence of HCC, sorafenib had been administered 6 months before admission. On admission, he exhibited consciousness disturbance, which gradually worsened. Two days later, both computed tomography and magnetic resonance imaging revealed an intra-axial tumor with perifocal edema and hemorrhage in the left frontal lobe. The tumor was successfully removed by craniotomy and pathological examination revealed that it was composed of moderately differentiated HCC cells. The day after surgical resection of the tumor, his consciousness returned to normal. Subsequently, he was treated with hepatic arterial infusion chemotherapy with 5-fluorouracil and cisplatin using an implanted port-catheter system. Surgical resection of intracranial metastasis of HCC would be important and meaningful in some cases.
\end{abstract}


Okimoto et al.: Successful Resection of Intracranial Metastasis of Hepatocellular Carcinoma

\section{Introduction}

Hepatocellular carcinoma (HCC) is one of the most common malignancies and has a high mortality rate worldwide [1]. HCC usually develops in chronically damaged liver caused by an infection with the hepatitis B virus (HBV) or hepatitis C virus (HCV), alcoholic abuse and nonalcoholic fatty liver disease [2]. Recent progress in diagnosis and new therapeutic approaches have improved the survival and prognosis of HCC. Notably, antiviral therapy such as nucleoside analogs in HBV carriers and interferon administration in HCV carriers reduced the risk of HCC $[3,4]$. However, chronic infection with HBV is often associated with the development of HCC at a young age and in the absence of liver cirrhosis.

Patients with HCC in advanced clinical stages still have a dismal prognosis. Not only tumor progression but also metastasis determines the prognosis of a wide range of malignancies including HCC. Tumor infiltration of blood vessels at the primary tumor site is responsible for metastasis and causes the formation of metastatic lesions in distant organs [5]. It has been believed that vascular invasion, which is one of the most significant features of HCC, contributes to intrahepatic or extrahepatic metastasis. Extrahepatic metastases of HCC are frequently observed in distant organs such as the lungs, regional lymph nodes, kidneys and bone marrow [6]. However, intracranial metastasis only accounts for a few percent of HCC patients [7]. Since intracranial metastasis frequently develops in patients with advanced tumors, palliative therapy rather than aggressive treatment tends to be selected. Therefore, both the benefits of treatment and the clinical course of intracranial metastasis of HCC remain to be elucidated.

Here, we describe a resected case of intracranial metastasis of HCC. Surgical resection of the tumor resulted in a dramatic recovery of consciousness and enabled further therapeutic intervention against HCC.

\section{Case Report}

A 32-year-old man was referred to our hospital because of nausea and vomiting. It appeared that the patient had been infected with HBV by vertical transmission. He had been monitored for chronic liver disease caused by HBV infection 2 years before. As multiple HCC was detected in the hepatic right lobe 1 year prior, he underwent a right hepatic trisectionectomy. Since his serum level of HBV-DNA was more than $5 \mathrm{log}$ copies $/ \mathrm{ml}$ at that time, a nucleoside analog, entecavir, was administered. Because of recurrence in the residual liver and lung metastasis detected 6 months after surgery, he was treated with an oral multikinase inhibitor, sorafenib. As adverse events such as liver dysfunction and eruption were observed 1 month after the administration of sorafenib, the dose was reduced from 800 to $200 \mathrm{mg} /$ day.

On admission, serum levels of hepatobiliary enzymes and markers for renal function such as blood urea nitrogen and creatinine were normal. The serum level of ammonia was $24 \mu \mathrm{g} / \mathrm{dl}$. Although blood count tests showed slight anemia (hemoglobin $11.2 \mathrm{~g} / \mathrm{dl}$ ) and thrombocytopenia $\left(12.6 \times 10^{4} / \mu \mathrm{l}\right)$, his white blood cell count was normal $(4,800 / \mu \mathrm{l})$. Serological tests exhibited the following HBV markers: hepatitis B surface antigen (HBsAg) positive, hepatitis $B$ surface antibody (HBsAb) negative, hepatitis $B$ envelope antigen (HBeAg) negative, hepatitis B envelope antibody (HBeAb) positive, and hepatitis B core antibody (HBcAb) positive. His serum level of HBV-DNA measured by real-time polymerase chain reaction was $2.9 \mathrm{log}$ copies $/ \mathrm{ml}$. Anti-HCV antibody was negative. Although the level of 
alpha-fetoprotein was elevated to $195,400 \mathrm{U} / \mathrm{ml}$, that of PIVKA-II was within the normal range $(32 \mathrm{U} / \mathrm{ml})$.

Of importance, the patient's Glasgow Coma Scale score was 11 points (E3V4M4), but no paresis was observed. However, the consciousness level gradually deteriorated and the Glasgow Coma Scale score decreased to 6 points (E2V2M2) on the second day of hospitalization. Non-enhanced computed tomography (CT) revealed an intra-axial tumor with surrounding edema in the left frontal lobe (fig. 1a). Severe edema caused a midline shift with subfalcine herniation of the cingulate gyrus. The tumor was found to be hyperdense on CT and hypointense on T2-star-weighted images of magnetic resonance imaging (MRI) consistent with hemorrhage (fig. 1b). A preoperative diagnosis of intracranial metastasis of HCC was made and a craniotomy was performed. Macroscopic examination of resected specimens revealed that the tumor was grayish-white and accompanied by necrosis and hemorrhage (fig. 2a). The size of the tumor was $75 \times 35 \times 33 \mathrm{~mm}$. Pathological examination revealed that it was a moderately differentiated HCC accompanied by necrosis and hemorrhage (fig. 2b).

The postoperative course was uneventful. The patient's state of consciousness returned to normal the day after surgery. Follow-up CT conducted 1 week after the craniotomy revealed both successful removal of the tumor and improvement in the subfalcine herniation (fig. 3a). Contrast-enhanced CT showed not only multiple residual HCCs with portal vein tumor thrombus (fig. 3b, c) but also multiple pulmonary metastases (fig. 3d). Subsequently, an implanted port-catheter system was constructed and he was treated with hepatic arterial infusion chemotherapy with 5 -fluorouracil and cisplatin. He is alive 5 months after the surgery and undergoing chemotherapy.

\section{Discussion}

Chronic infection with HBV is known to be a major risk factor for cirrhosis and HCC [8]. Lamivudine was the first nucleoside analog to be approved for the treatment of patients with chronic HBV infection, but drug resistance frequently develops during long-term lamivudine therapy [9]. In contrast, treatment with entecavir, another nucleoside analog against HBV, rarely results in resistance [9]. Recent reports showed that both drugs reduced the risk of developing HBV-related HCC, although an unfavorable virological response to the treatment failed to decrease the incidence of HCC in patients with cirrhosis [10]. In our case, the patient acquired HBV vertically and developed cirrhosis and HCC. When he started to take entecavir orally after right hepatic trisectionectomy, the HBV-DNA decreased but did not disappear in the peripheral blood.

Extrahepatic metastases are detected in 14-37\% of HCC patients [11], although intracranial metastasis only accounts for a small percentage of extrahepatic metastases. Since intracranial metastasis of HCC frequently causes serious complications such as intracranial hypertension, hemorrhage and cerebral edema, the prognosis of HCC is dismal. Choi et al. [12] reported that surgical resection and/or whole brain radiation therapy significantly prolonged survival compared with steroid treatment alone. It has been also documented that aggressive treatments such as resection and/or whole brain radiation therapy, single intracranial metastasis, and good liver reserve function serve as a prognostic factor [12]. Together, these findings indicate that sufficiently aggressive treatment may improve the prognosis for some patients with intracranial metastasis of HCC. In our case, there was only one metastatic lesion and the patient's liver reserve function was good (Child-Pugh A). Successful resection of the intracranial tumor improved his level of consciousness dramatically and 
Okimoto et al.: Successful Resection of Intracranial Metastasis of Hepatocellular Carcinoma

enabled further therapeutic approaches against HCC. Together, it seems that surgical resection of intracranial metastasis of HCC contributed to the prolonged survival in this case.

In conclusion, we report a rare case of intracranial metastasis of HCC resected successfully. Considering that most extrahepatic metastases of HCC developed in patients with advanced intrahepatic lesions and vascular invasion [13], it is important to be aware of extrahepatic spread in patients with advanced HCC. In addition, it is necessary to determine whether aggressive treatment such as surgical resection improves the prognosis for intracranial metastasis of HCC. Further examinations in large numbers of patients are necessary for both an understanding of the mechanisms underlying intracranial metastasis of HCC and the development of therapeutic approaches.

\section{Disclosure Statement}

The authors have no conflict of interest.

\section{References}

1 Okuda K: Hepatocellular carcinoma: recent progress. Hepatology 1992;15:948-963.

2 El-Serag HB: Hepatocellular carcinoma. N Engl J Med 2011;365:1118-1127.

-3 Papatheodoridis GV, Lampertico P, Manolakopoulos S, Lok A: Incidence of hepatocellular carcinoma in chronic hepatitis B patients receiving nucleos(t)ide therapy: a systematic review. J Hepatol 2010;53: 348-356.

-4 Yoshida H, Arakawa Y, Sata M, Nishiguchi S, Yano M, Fujiyama S, Yamada G, Yokosuka O, Shiratori Y, Omata $\mathrm{M}$ : Interferon therapy prolonged life expectancy among chronic hepatitis $\mathrm{C}$ patients. Gastroenterology 2002;123:483-491.

5 Pantel K, Brakenhoff RH, Brandt B: Detection, clinical relevance and specific biological properties of disseminating tumour cells. Nat Rev Cancer 2008;8:329-340.

6 Chang L, Chen YL, Kao MC: Intracranial metastasis of hepatocellular carcinoma: review of 45 cases. Surg Neurol 2004;62:172-177.

7 Seinfeld J, Wagner AS, Kleinschmidt-DeMasters BK: Brain metastases from hepatocellular carcinoma in US patients. J Neurooncol 2006;76:93-98.

-8 Arzumanyan A, Reis HM, Feitelson MA: Pathogenic mechanisms in HBV-and HCV-associated hepatocellular carcinoma. Nat Rev Cancer 2012;13:123-135.

-9 Lok AS, Zoulim F, Locarnini S, Bartholomeusz A, Ghany MG, Pawlotsky JM, Liaw YF, Mizokami M, Kuiken C; Hepatitis B Virus Drug Resistance Working Group: Antiviral drug-resistant HBV: standardization of nomenclature and assays and recommendations for management. Hepatology 2007;46:254-265.

10 Zoutendijk R, Reijnders JG, Zoulim F, Brown A, Mutimer DJ, Deterding K, Hofmann WP, Petersen J, Fasano M, Buti M, Berg T, Hansen BE, Sonneveld MJ, Wedemeyer H, Janssen HL; for the VIRGIL Surveillance Study Group: Virological response to entecavir is associated with a better clinical outcome in chronic hepatitis B patients with cirrhosis. Gut 2012, Epub ahead of print.

-11 Kashima M, Yamakado K, Takaki H, Kaminou T, Tanigawa N, Nakatsuka A, Takeda K: Radiofrequency ablation for the treatment of bone metastases from hepatocellular carcinoma. AJR Am J Roentgenol 2010;194:536-541.

12 Choi HJ, Cho BC, Sohn JH, Shin SJ, Kim SH, Kim JH, Yoo NC: Brain metastases from hepatocellular carcinoma: prognostic factors and outcome: brain metastasis from HCC. J Neurooncol 2009;91:307-313.

13 Katyal S, Oliver JH 3rd, Peterson MS, Ferris JV, Carr BS, Baron RL: Extrahepatic metastases of hepatocellular carcinoma. Radiology 2000;216:698-703.

Kenichiro Okimoto and Sadahisa Ogasawara equally contributed to this work. 


\begin{tabular}{|c|c|c|}
\hline \multirow{3}{*}{$\begin{array}{r}\text { Case Reports in } \\
\text { Gastroenterology }\end{array}$} & \multirow{2}{*}{\multicolumn{2}{|c|}{ Case Rep Gastroenterol 2013;7:182-187 }} \\
\hline & & \\
\hline & DOI: $\underline{10.1159 / 000350673}$ & $\begin{array}{l}\text { (c) } 2013 \text { S. Karger AG, Basel } \\
\text { www.karger.com/crg }\end{array}$ \\
\hline
\end{tabular}
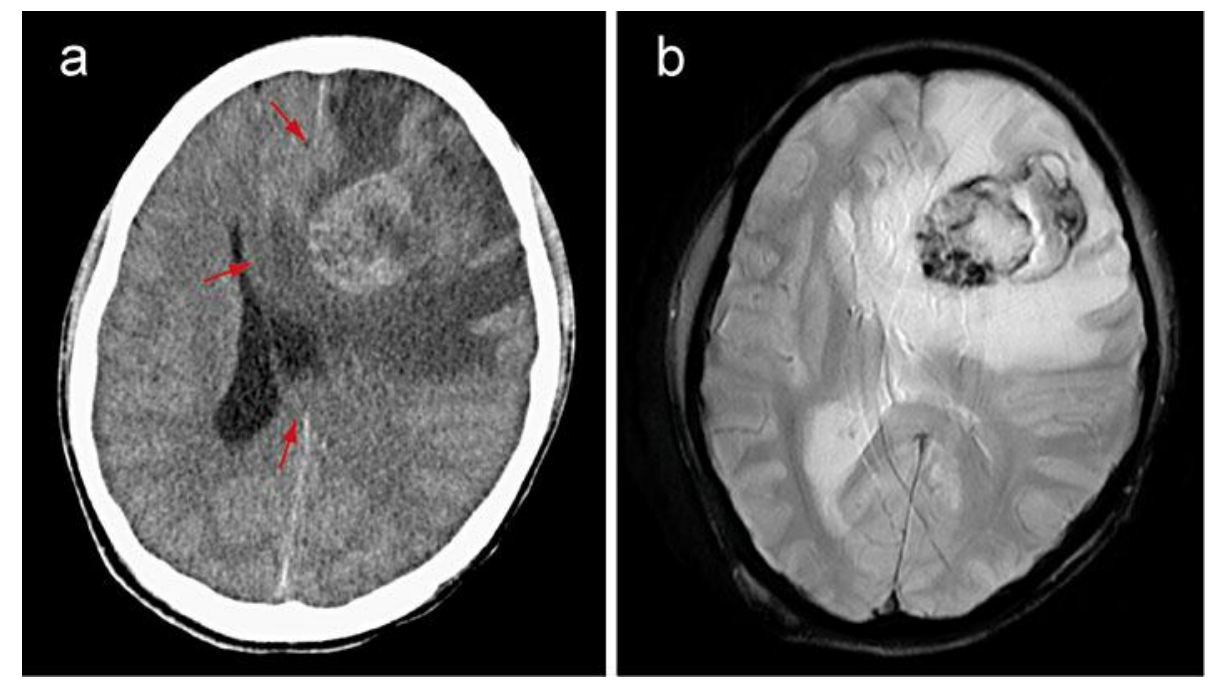

Fig. 1. Findings of CT and MRI. a The CT scan shows a hyperdense tumor with massive edema causing subfalcine herniation (arrows). b The T2-star-weighted image demonstrates a mass with a hypointense signal area consistent with hemorrhage.
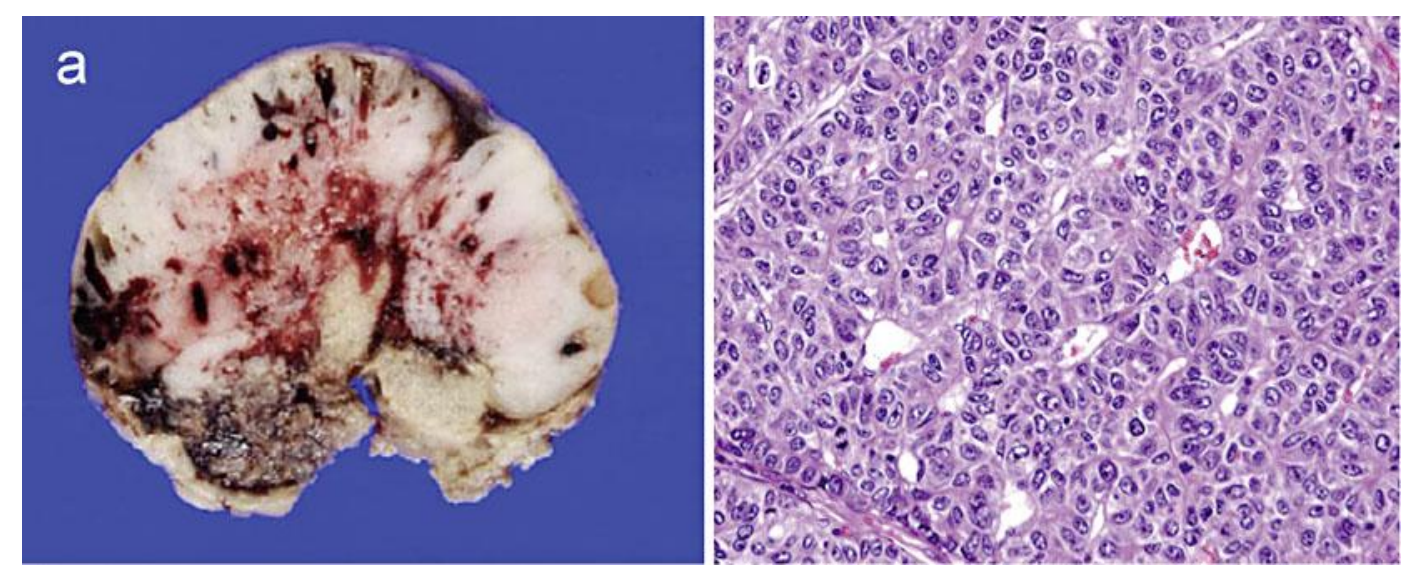

Fig. 2. Pathological examination of the intracranial tumor. a Macroscopic findings of the resected tumor. b H\&E staining of the tumor, $\times 200$. 


\begin{tabular}{|c|c|c|}
\hline \multirow{3}{*}{$\begin{array}{r}\text { Case Reports in } \\
\text { Gastroenterology }\end{array}$} & \multirow{2}{*}{\multicolumn{2}{|c|}{ Case Rep Gastroenterol 2013;7:182-187 }} \\
\hline & & \\
\hline & DOI: $\underline{10.1159 / 000350673}$ & $\begin{array}{l}\text { (c) } 2013 \text { S. Karger AG, Basel } \\
\text { www.karger.com/crg }\end{array}$ \\
\hline
\end{tabular}
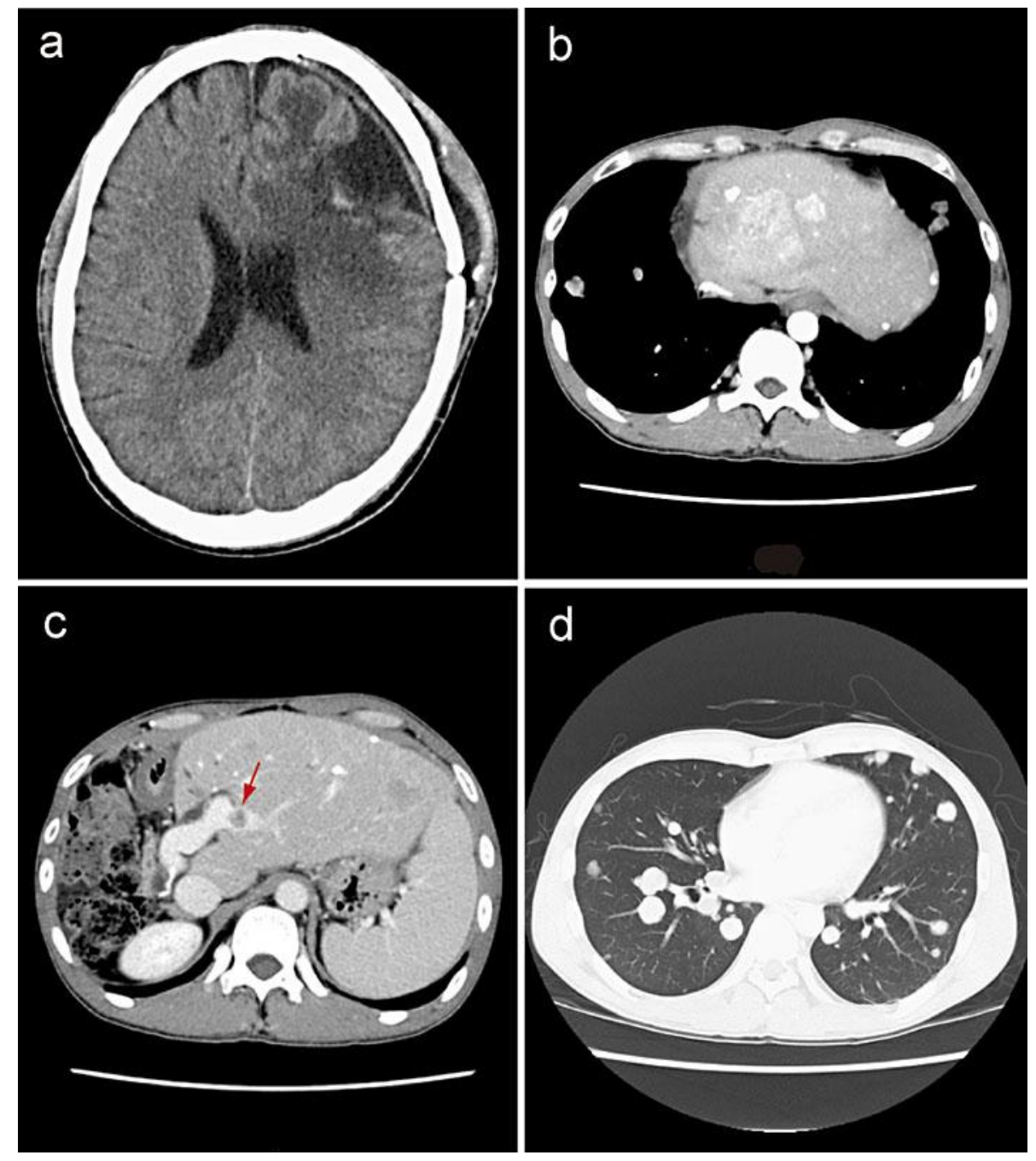

Fig. 3. CT images after surgical resection of the intracranial tumor. a Non-enhanced CT shows that the tumor has been totally removed and the midline shift is improved. b, c Contrast-enhanced CT reveals multiple residual HCCs (b) and portal vein tumor thrombus in a segment 2 portal branch (c, arrow). d Multiple pulmonary metastases are depicted. 